\title{
GUN CARRYING AMONG ADOLESCENTS
}

\author{
David Hemenway," Deborah Prothrow-STith," Jack M. \\ BERgSTEIN,"** ROSEANNA ANDER, ${ }^{* * *}$ AND BRUCE P. KENNEDY****
}

INTRODUCTION

Mortality from almost every type of injury has decreased during the past decade. ${ }^{1}$ The major exception is death from firearms. Gun deaths have risen in the United States since 1985, with the largest increase occurring among adolescents. $^{2}$

Gun purchases by minors are illegal under federal law. ${ }^{3}$ Handgun possession by individuals under eighteen years of age is also unlawful. ${ }^{4}$ "Although the question of restricting firearm ownership and usage is contentious .... few argue that adolescents should have unsupervised access to firearms or other lethal weapons. Fewer still argue that adolescents should be permitted to carry loaded firearms or other lethal weapons at school or on city streets."

One of the national health objectives for the year 2000 is to reduce by twenty percent the incidence of weapon carrying by adolescents aged fourteen through seventeen. ${ }^{6}$ Unfortunately, "little is known about the determinants of

\section{Copyright $(\odot) 1996$ by Law and Contemporary Problems}

This research was partially funded by the Educational Fund to End Handgun Violence and the Harvard Injury control Center, which is supported in part by the Centers for Disease Control and Prevention.

* Professor, Department of Health Policy and Management, Harvard School of Public Health.

** Professor, Department of Health Policy and Management, Harvard School of Public Health.

*** Assistant Professor of Surgery, Medical College of Wisconsin.

**** Graduate Research Assistant, Harvard Injury Control Center, Harvard School of Public Health.

***** Director, Public Health Practice Initiative, Harvard School of Public Health.

1. STATISTICAL ABSTRACT OF THE U.S. 99, no. 134 (1995) ("Deaths and Death Rates from Accidents, by Type: 1970 to $1992 ")$.

2. See Alfred Blumstein \& Daniel Cork, Linking Gun Availability to Youth Gun Violence, 59 LAW \& CONTEMP. PROBS. 5 (Winter 1996); NATIONAL CTR. FOR INJURY PREVENTION \& CONTROL, MORTALITY DATA (last modified 1993) <www.cdc.gov/ncipc/osp/us9390/ofarm.htm>.

3. James D. Wright et al., Kids, Guns, and Killing Fields, SOCIETY, Nov.-Dec. 1992 (citing 1968 Gun Control Act, 18 U.S.C. $\S \S 921-928$ (1996)).

4. HANDGUN CONTROl INC., SUMmary OF THE Firearms PROVISIONS OF THE Violent CRIME CONTROL AND LAW ENFORCEMENT ACT OF 1994, at 3 (1994).

5. Public Health Service, U.S. Dep'T OF Heal th and Human Services, Pub. No. 91-50212, Healthy People 2000: National Health Promotion AND Disease PREVENTION OBJeCtives 236 (1990).
6. Id. 
weapon carrying among adolescents"; "there has been little credible research on where, how, and why juveniles acquire, carry, and use guns." ${ }^{\prime 8}$ In the report of the Carter Center on the crisis of children and firearms, the first research suggestion is to "determine which kids are carrying firearms and why."

The study reported here provides information about which teens carry guns in two northern cities. The article explains and applies the public health contagion model and provides policy suggestions to reduce gun carrying among adolescents.

\section{II}

\section{The "HANDs without Guns" Adolescent FIREARMS Study}

\section{A. Literature Review}

Previous studies have found that adolescent gun carrying is common among inner-city youth. Among junior high school students in Washington, D.C., for example, twenty-five percent of males and four percent of females have carried a gun. ${ }^{10}$ Among New York City high school students, seven percent reported carrying a handgun in the preceding thirty days. ${ }^{11}$ In South Carolina, approximately eight percent of white male high school students and thirteen percent of black male high school students had carried a gun within the preceding thirty days. ${ }^{12}$

Another study of inner-city high school students found that twenty-two percent carried a gun outside of school. ${ }^{13}$ In a survey of inner-city male students (mean age sixteen), twelve percent of all respondents reported carrying a gun all or most of the time, and another twenty-three percent carried one occasionally. $^{14}$ The 1993 Youth Risk Behavior Surveillance, a nationally representative sample of students in grades nine through twelve, found that nearly fourteen percent of the males had carried a gun in the previous thirty days. ${ }^{15}$

7. Daniel W. Webster et al., Weapon Carrying among Inner-City Junior High School Students: Defensive Behavior vs. Aggressive Delinquency, 83 AM. J. PUB. HeAlTH 1604 (1993).

8. Wright et al., supra note 3 , at 88.

9. The Carter Center, Not Even One: THe report of the Carter Center ConsultaTION ON THE CRISIS OF CHILDREN AND FIREARMS 23 (1994).

10. Webster et al., supra note 7, at 1604-05.

11. Centers for Disease Control and Prevention, Violence-Related Attitudes and Behaviors of High School Students-New York City, 1992, 270 JAMA 2032 (1993).

12. Robert F. Valois et al., Correlates of Aggressive and Violent Behaviors among Public High School Adolescents, 16 J. AdOLESCENT HEALTH 27, 29 (1995).

13. Joseph F. Sheley et al., Gun-Related Violence in and around Inner-City Schools, $146 \mathrm{~J}$. DISEASES CHILD. 679 (1992).

14. JOSEPH F. SHELEY \& JAMES D. WRIGHT, NAT'L INST. OF JUSTICE, RESEARCH IN BRIEF: GUN ACQUiSITION AND POSSESSION IN SELECTED JUVENILE SAMPLES 5 (1993).

15. Center for Disease Control and Prevention, Youth Risk Behavior Surveillance-United States 1993, MORBIDITY \& MORTALITY WEEKLY REP. 23, tbl. 4 (Mar. 24, 1995). 
In previous studies, gun carrying has been associated with the following factors: knowing more victims of violence, ${ }^{16}$ having been threatened with a gun ${ }^{17}$ having been victimized with a gun ${ }^{18}$ having friends and relatives who carry guns; ${ }^{19}$ starting fights; ${ }^{20}$ having been arrested; ${ }^{21}$ and engaging in drug and other criminal activity. ${ }^{22}$ Our study employed a questionnaire that permitted us to examine many correlates of gun carrying that had not been investigated previously.

\section{B. Methods}

In the spring of 1995, an in-class survey was conducted to provide baseline data for an evaluation of "Hands Without Guns," which is an intervention designed by the Educational Fund to End Handgun Violence to change adolescent attitudes toward and behaviors about guns and violence. The survey was administered in the classroom to seventh- and tenth-grade students at twelve inner-city schools in two large cities in the Northeast and Midwest. Responses were obtained from 752 seventh-graders and 440 tenth-graders. Because responses did not differ significantly between the two cities, the results are combined for reporting purposes.

In the primary analysis, the dependent variable is the response to the question "Have you ever carried a concealed gun with you anywhere?" An open-ended follow-up question asked, "If you have ever carried a gun, what made you decide the very first time to carry a gun?"

The independent variables are divided into three groupings: (1) demographics (for example, gender and grade level); (2) personal characteristics, which are sometimes called "behavioral risk factors" (for example, cigarette and alcohol consumption); and (3) gun-related variables (for example, whether a family member had been shot). In the tables that appear at the end of this article, the independent variables are dichotomized for reporting purposes. Alternative formulations of these variables do not significantly affect the results.

The four demographic variables are gender, grade level (seventh versus tenth), family environment (whether there are two parents in the home versus one parent or other family structure), and home ownership (whether the family owns versus rents, or the respondent does not know).

The four behavioral risk factor variables are cigarette consumption (zero cigarettes consumed last week versus one or more), binge drinking (no occasion with four or more servings of alcohol in the past thirty days versus one or more

16. Webster et al., supra note 7, at 1606.

17. Joseph F. Sheley \& Victoria E. Brewer, Possession and Carrying of Firearms Among Suburban Youth, 110 PUB. HEALTH REPS. 24 (1995).

18. Sheley et al., supra note 13 , at 679.

19. Id. at 681 .

20. Webster et al., supra note 7 , at 1606.

21. Id.

22. Sheley \& Brewer, supra note 17 , at 24 . 
occasions), academic record (average or above average versus below average), and confidence in his or her ability to stay out of fights.

The three gun-related variables are answers to the following survey questions: (1) "Has anyone in your immediate family been the victim of a shooting?"; (2) "Are there a lot of shootings in your neighborhood?"; and (3) "Have you ever seriously discussed guns with your parents or guardians?".

The results are reported using two-by-two tables and multivariate logistic regression analysis. ${ }^{23}$ Responses to various attitudinal questions concerning guns are also reported, but they are not included as independent variables in the regression. One attitudinal question asked the adolescents whether they would prefer to live in a society where there were more guns, fewer guns, or the same number of guns. Another question asked whether they would prefer to live in a society where it was easy for teens to get guns, very difficult for teens to get guns, or impossible for teens to get guns. A third question asked if more of their classmates gained access to guns, would that make them feel more safe, less safe, or no change in how safe they felt.

Other questions asked whether they could get a gun if they wanted one, how often in the previous thirty days they had had a gun at school, and if more of their classmates brought guns to school, would they be more likely to bring a gun to school, less likely, or would it have no effect?

The generalizability and validity of the results are limited by a variety of factors. The sample is limited geographically to two cities, and we have data from only twelve schools in these cities. Although we believe these schools constitute a fairly representative sample of inner-city public schools in these two locations, the schools were chosen by convenience rather than at random. The results are also limited somewhat by attendance patterns. Only students in the schools were surveyed; truants and drop-outs, who were not questioned, probably have a higher likelihood of carrying guns. ${ }^{24}$

Further limitations may have been caused by some of the questionnaire's vague terms, which all respondents may not have interpreted in the same way. For example, when they were asked whether there were "a lot of shootings in their neighborhood," respondents may have had different understandings of what constitutes "a lot of shootings" and what is meant by "their neighborhoods."

Finally, the results were self-reported and are not validated. While the survey was anonymous, some of the respondents may not have known or been inclined to tell the truth. Inaccurate reporting could be due to a variety of factors: for example, social desirability responses, recall bias, and non-candid

23. These results exclude respondents with missing values for any of the variables. The significance levels of all variables are unchanged when separate dummies are created for the missing values for each independent variable and all respondents are included in the analysis.

24. RiCHARD JESSOR ET AL., BEYOND ADOLESCENCE: PROBLEM BEHAVIOR AND YOUNG ADULT DEVELOPMENT 279-81 (1991) (discussing the interrelatedness of problem behaviors). 
responses. $^{25}$ Adolescent males in particular may be inclined to brag about their exploits. However, the results suggest that the respondents were fairly honest about their academic standing (a plurality of students ranked themselves as average, with only slightly more above average than below average), and they do not seem to brag about their cigarette smoking (only nine percent said they had smoked even one cigarette in the past week).

\section{Results}

Seventeen percent ${ }^{26}$ of the adolescents surveyed have carried a concealed gun: twenty-nine percent of the male tenth-graders; twenty-three percent of the male seventh-graders; twelve percent of the female tenth-graders; and eight percent of the female seventh-graders (Table 1). ${ }^{27}$ The overwhelming majority of these students gave protection or self-defense as their reason for having carried a concealed gun.

Demographic factors associated with carrying a concealed gun are being male (Multivariate Odds Ratio ("OR") 5.1; $95 \%$ Confidence Interval ("CI") 3.1, 8.1) and being in a higher grade (OR 2.1; CI 1.5, 3.0) (Table 2). Living in a family that owns rather than rents a home and living with both parents have no significant effect on concealed gun carrying.

All four behavior risk factor variables are significantly associated with gun carrying: smoking (OR 5.5; CI 3.4, 9.0); alcohol use (OR 1.8; CI 1.2, 2.7); poor academic performance (OR 1.7; CI 1.2, 2.3); and lack of confidence in staying out of fights (OR 2.7; CI 1.9, 3.8). However, given the small percentage of these adolescents who smoke or binge drink, most of the youths who carry guns are not smokers (seventy-six percent) and most are not binge drinkers (seventythree percent).

The three gun variables-victim in family, shootings in neighborhood, and discussions about guns with parents or guardians-are all significant. The nearly thirty percent of the students who report that someone in their immediate families were victims of a shooting are significantly more likely to have carried a concealed gun (OR 2.3; CI 1.6, 3.3). Teens in neighborhoods with a lot of shootings are also more likely to have carried a gun (OR 2.9; CI 2.0, 4.1), as are the respondents who have not had a serious discussion about guns with their parents or guardians (OR 1.5; CI 1.0, 2.2).

Examining females separately, only four of the independent variables are significant predictors of gun carrying: smoking, lack of confidence in the ability to stay out of fights, shootings in the neighborhood, and having a relative who has been shot (not shown in the tables). When males are examined separately, the significance of all independent variables is the same as in the full regression.

25. LUANN ADAY, DESIGNING AND CONDUCTING HEALTH SURVEYS: A COMPREHENSIVE GUIDE $131-38,169$ (1989).

26. Percentages cited in the text are given after eliminating missing responses.

27. All tables appear in the Appendix. 
Adolescents in the survey see guns as a serious problem. Eighty-seven percent would prefer to live in a society where there are fewer guns; only two percent want a society with more guns (Table 3). Similarly, seventy-six percent would like it to be impossible for teens to get guns, and nineteen percent would like to make it very difficult, while only five percent want it to be easy for teens to get guns. Sixty percent say they would feel less safe if more of their classmates gained access to guns; seven percent say they would feel safer, and thirty-three percent say they would feel no change in their safety.

Unfortunately, it is currently easy for these youths to get guns: seventeen percent have already carried a concealed firearm, and forty-two percent say they could get a gun if they wanted one.

\section{A Contagion Model}

A contagion model may be helpful in understanding why so many of these youths carry guns.

Firearm ownership creates externalities. For example, owning a gun could increase the safety of neighbors (by helping to protect neighbors who are attacked, for example) or decrease the safety of neighbors (by increasing the likelihood that a gun will be used in a dispute among neighbors, for example). Survey evidence indicates that the vast majority of adults believe that gun ownership creates negative externalities: they feel less safe as others in the community acquire firearms. ${ }^{28}$

The carrying of firearms similarly creates positive and negative externalities. The limited evidence available suggests that gun carrying has net costs rather than net benefits, at least in terms of homicide. ${ }^{29}$

Both gun owning and carrying also create what have been called "replicative externalities," $" 30$ where one action increases the likelihood that similar actions will occur. For example, standing up to get a better view during a parade increases the likelihood that others will also stand up. Similarly, gun carrying by some may increase the likelihood that others will carry guns.

Various analytical approaches have been used to help illuminate the effects of replicative externalities. Thomas Schelling, for example, used the idea of a "tipping model" to discuss the case in which a white family moving out of a neighborhood increases the likelihood that other white families will also move out. $^{31}$

28. David Hemenway et al., Firearms and Community Feelings of Safety, 86 J. CRIM. L. \& CRIMINOLOGY 121-32 (1995).

29. David McDowall et al., Easing Concealed Firearm Laws: Effects on Homicide in Three States, 86 J. CRIM. \& CRIMINology 193-206 (1995).

30. David Hemenway et al., An Arson Epidemic, 15 J. BEHAV. ECON. 17-18 (1986).

31. See Thomas C. Schelling, Dynamic Models of Segregation, 1 J. MATH. SOC. 181-86 (1971). 
An arms race analogy has also been used to analyze replicative externalities. An increase in gun ownership among homeowners may force burglars and robbers to become better armed. ${ }^{32}$

Reaction functions are analytic tools that are sometimes used to depict equilibriums when replicative externalities exist. For example, how friendly one is toward you is a function of your friendliness toward that person, and vice versa. How often another person carries a gun may depend on how often you carry one, and vice versa.

For public health researchers, the contagion model is the most familiar approach for analyzing replicative externalities. The presence of one individual with an infectious disease increases the likelihood that others will become infected with the same disease. Interest in infectious disease epidemiology has increased in recent years with the emergence of major infections such as AIDS in the developed world. Contagion models have become more sophisticated and more accurate through the use of computer simulation.

The simplest disease contagion model is Bernoulli's Susceptible, Infected, Resistant ("SIR") model composed of three differential equations. ${ }^{33}$ At any moment, every individual in the community falls into one of the three categories. The classic SIR model examines the changes over time in the number of individuals in each of these three categories.

Two of the key variables of interest in the contagion model are the probability of transmission of the infection from one individual to another and the presence of public policy interventions, such as immunizations, which are designed to reduce the probability of infection or to move individuals from the susceptible to the resistant state.

In a contagion model for gun carrying, the infected are those who currently carry firearms, the susceptible are those who can be influenced to carry firearms by the fact that others are armed, and the resistant are those who will not carry a gun under any circumstances.

The outcome of even a simple SIR contagion model is not readily apparent from the choice of assumptions, though approximate solutions can be determined through computer simulation. Probably the most intriguing and important finding from such simulations is that very small changes in the parameters can lead to enormous changes in the ultimate "history" of the disease.

\section{E. Evidence}

Contagion models are dynamic and are not easily testable with crosssectional data. In addition, our cross-sectional survey was not specifically

32. Gary S. Green, Citizen Gun Ownership and Criminal Deterrence: Theory, Research and Policy, 25 CRIMINOLOGY 71 (1987).

33. ROY M. ANDERSON \& ROBERT M. MAY, INFECTIOUS DISEASES OF HUMANS: DYNAMICS AND CONTROL 6-7 (1991); JOHAN GIESECKE, MODERN INFECTIOUS DISEASE EPIDEMIOLOGY (1994). 
designed to examine the contagion model. However, responses to a few of the survey questions provide some evidence about the possible existence of replicative externalities.

Most of the surveyed adolescents feel less safe rather than more safe as their classmates gain access to guns. If feeling less safe increases the desire of these students to obtain guns themselves, this would form the basis for a contagion model of gun acquisition. Gun acquisition reduces others' perceptions of safety, which in turn increases gun acquisition.

Living in a neighborhood with many shootings is associated with gun carrying by these adolescents. If shootings lead to increased carrying, and if carrying leads to more shootings, these relationships would be examples of replicative externalities both for shootings and for carrying. More shootings increase gun carrying, which increases shootings, which further increase gun carrying.

A clear-cut question to test the contagion/carrying model would have been the following: "If more of my peers carry guns, I am (a) more, (b) less, or (c) equally likely to carry a gun." A question on the survey tested a contagion/bringing-guns-to-school model: "If more of my classmates bring guns to school, this makes it more likely that I will bring a gun to school, less likely that I will bring a gun to school, has no effect." If there are replicative externalities, an increase in the number of students bringing guns to school could have an escalation effect by causing others to bring guns to school.

Fewer than three percent of the adolescents reported having a gun at school in the past month. Surprisingly, twenty percent said they would be less likely to bring a gun if more of their classmates carried, and only eleven percent said they would be more likely to carry. Sixty-nine percent said others bringing a gun would not affect them (Table 4).

There appears to be a dampening rather than a multiplicative effect. However, a contagion model might exist if most of the twenty percent are the "resistant," who would probably not bring a gun to school under any circumstances, while most of the eleven percent are the "susceptible," who would actually bring guns to school in response to an increase in guns at school.

Those who have ever carried a concealed gun are probably most susceptible to carrying a gun to school, and those who have never carried a concealed gun are probably most likely to be one of the resistant. Among those who have ever carried, thirty-four percent are more likely to bring a gun to school if others do and only eight percent are less likely. The pattern is reversed among those who have never carried: only seven percent are more likely to bring a gun to school if others do, while twenty-two percent would be less likely (table 4). Such evidence is consistent with a contagion model.

\section{F. Policy Implications}

The findings of the survey suggest various conclusions regarding appropriate policies to reduce gun carrying among adolescents in the inner city: 
(1) The problem of teen gun carrying starts early. Twenty-three percent of seventh-grade inner-city males in our sample have already carried a concealed gun. A policy aimed at the demand side needs to address the concerns of twelve- and thirteen-yearolds as well as older adolescents.

(2) Some people are far more likely to engage in risky behaviors than others. ${ }^{34}$ In our survey, more than half of the males who smoke have also carried a gun (not shown); similarly, more than half of the males who binge drink have carried a gun (not shown). If interventions are to be targeted, they should be targeted toward these youths and should address multiple behaviors. However, since relatively few males either smoke or binge drink, a fully targeted intervention would not reach most gun carriers. Put another way, targeting only smokers or drinkers would miss many gun-carrying adolescents. However, since such a high percentage of smokers and drinkers also carry guns, cigarette and alcohol interventions should also address gun carrying.

(3) Training in conflict resolution might reduce gun carrying. Holding other factors constant, adolescents who lack confidence in their ability to stay out of fights are far more likely to carry a gun than those who have confidence.

(4) Frank family discussions about guns may reduce gun carrying. Children who have discussed guns seriously with their parents are significantly less likely to carry them than those who have not. Of course, correlation does not necessarily indicate cause and effect. It may just be that the families who have such discussions are those in which the children would tend not to carry firearms for other reasons.

(5) Many of the survey results suggest a contagion model of gun carrying. In a contagion model, the ultimate impact of an intervention is often far greater than the actual size of the intervention. Isolating a few individuals who are carriers, or immunizing some of the potential infected, could have a multiplicative effect.

III

\section{CONCLUSION}

Gun violence is a common experience of the adolescents who participated in the survey. Twenty-eight percent report that an immediate family member

34. JESSOR ET AL, supra note 24, at 111-27; David Hemenway, Nervous Nellies and Dangerous Dans, 12 J. POL'Y ANAL. \& MGMT. 359, 360 (1993). 
has been shot. Seventeen percent of the seventh- and tenth-graders have carried a concealed gun.

The reason given for gun carrying is overwhelmingly that of self-protection. However, it appears that carrying firearms makes other students feel less safe, which increases the likelihood that they will in turn carry guns. Following their own perceived self-interest, too many teens carry guns, and they are all worse off.

Our study suggests the importance of both supply-side and demand-side approaches to reducing adolescent gun carrying. Supply-side efforts to make firearms less available to inner-city teens have the support of the students in the study. The large majority would prefer to live in a world where it was not only very difficult but impossible for teenagers to obtain guns.

Our study also suggests possible demand-side policies that might prove effective in reducing gun carrying by inner-city adolescents. These policies include encouraging frank family discussions about firearms, providing training in conflict resolution to teenagers, and targeting interventions to youth who engage in other high-risk behaviors.

Measures that increase teen safety and decrease the need for self-protection are essential in helping to reduce adolescent gun carrying. The results of contagion modeling suggest that small initial changes in gun carrying can have multiplicative effects. 


\section{APPENDIX}

\section{TABLE 1}

\section{Concealed Gun CARRYing By GRAde AND Gender}

Positive responses to "Have you ever carried a concealed gun with you anywhere?"

\begin{tabular}{lcc} 
& Sample Size & \multicolumn{2}{c}{$\begin{array}{c}\text { Percentage that } \\
\text { Carried Concealed Guns }\end{array}$} \\
\cline { 2 - 3 } 10th-Grade Boys & 201 & 29 \\
10th-Grade Girls & 237 & 12 \\
7th-Grade Boys & 376 & 23 \\
7th-Grade Girls & 364 & 8 \\
All Respondents & 1178 & 17
\end{tabular}




\section{TABLE 2}

CORRELATES OF CONCEALED GUN CARRYING

Variable

Total

Demographics

Male

Female

7 th grade

10th grade

Lives w/both parents

Other

Family owns home

Rent/don't know

Behavioral Risk Factors

Smokes

Nonsmoker

$>4$ serv. alcohol at least

once/month

Not $>4$ serv. alcohol

Average or better student

Below average

Confident can stay out of fights

Not confident

104

1071

129

1040

888

267

631

496

Percentage

that Carried

Concealed

Gun

17

578

601

752

440

470

430

625

Gun Related

Family member shot

No family member shot
339

822
Odds fidence

Ratio Interval
14

19

19

16

16
19

25

10

46

14

41

1.8

$1.2,2.7$

14

15

23

10

$\begin{array}{lll}10 & 2.7 & 1.9,3.8\end{array}$

$\begin{array}{lll}10 & 2.7 & 1.9,3.8\end{array}$

26

$5.1 \quad 3.1,8.1$

$2.1 \quad 1.5,3.0$

$0.8 \quad 0.6,1.2$

$0.8 \quad 0.6,1.1$

$5.5 \quad 3.4,9.0$

$1.7 \quad 1.2,2.3$

28

$2.3 \quad 1.6,3.4$ 
A lot of shootings in neighborhood

Not a lot of shootings in neighborhood

333

30

$2.9 \quad 2.1,4.1$

817

12

Discussed guns w/parents

720

13

443

19

$1.5 \quad 1.0,2.2$

Did not discuss w/parents

*Logistic Regression included 986 cases due to missing data 
TABLE 3

TEEN ATTITUDES ABOUT GUNS

Percentage that would prefer to live in a society where there were

Have carried gun

Haven't carried gun

Total
Fewer Guns

71

90

87
More Guns 8

1

2
Same number

20

9

11

Percentage that would prefer to live in a society where it was

Impossible for Very difficult for Easy for teens

Have carried gun

Haven't carried gun

Total teens to get guns teens to get guns to get guns

51

82

76
30

16

19
19

2

5

If more classmates gain access to guns, percentage that would feel

Have carried gun

Haven't carried gun

Total

\begin{tabular}{c} 
Less Safe \\
\hline 36 \\
65 \\
60
\end{tabular}

60
More Safe 13

6

7
The Same

51

29

33

Percentage that could/could not get a gun if they wanted one:

Have carried gun

Haven't carried gun

Total
Could

87

33

42
Could Not

4

36

31
Don't Know 9

31

27 
TABLE 4

IS BRINGING GUNS TO SCHOOL CONTAGIOUS?

Percentage more/less likely to bring guns to school if more classmates bring guns:

Have carried gun

\begin{tabular}{cccc} 
More Likely & & Less Likely & No Effect \\
\hline 34 & 8 & & 58 \\
7 & 22 & 71 \\
11 & 20 & 69
\end{tabular}

Total

11

20

69 
